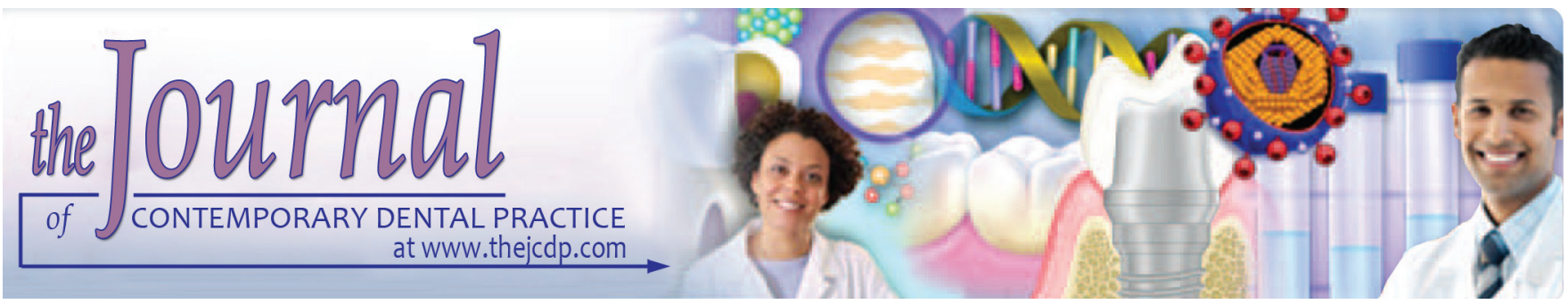

\title{
Risk Factors associated with Dental Implant Failure: A Study of 302 Implants placed in a Regional Center
}

\author{
${ }^{1}$ Mehmet Oztel, ${ }^{2}$ Wojciech M Bilski, ${ }^{3}$ Arthur Bilski
}

\section{ABSTRACT}

Aim: The aim of this research is to determine which risk factors are associated with dental implant failure and survival.

Materials and methods: Data pertaining to patients who received one or more dental implants from 2011 to 2013 in a regional center were retrospectively reviewed. This included a total of 302 Biomet 3i NanoTite Tapered Certain implants placed in 177 patients. All patients were followed up until the end of 2015.

Results: This study found an overall success rate of $95 \%$. Statistically significant factors that were found to affect implant survival were implant length, surgical technique, and presence of diabetes mellitus DM. Age, gender, body mass index (BMI), implant site, smoking, and variable operators were not found to have any significant implant on implant survival.

Conclusion: This study has demonstrated that the incidence of implant failure and its complications is affected by a number of important factors that clinicians should consider when assessing patients. A follow-up study with a larger sample size, longer follow-up period, and details of the type of prosthetic rehabilitation would be beneficial in producing more definitive conclusions which may improve clinical practice.

Clinical significance: Dental implants play an important role in modern-day dental rehabilitation. It is vital that clinicians understand the impact of variable risk factors on implant survival. This study will add to the growing literature on the subject.

Keywords: Complications, Dental implants, Failure.

How to cite this article: Oztel M, Bilski WM, Bilski A. Risk Factors associated with Dental Implant Failure: A Study of 302 Implants placed in a Regional Center. J Contemp Dent Pract 2017;18(8):705-709.

\footnotetext{
${ }^{1}$ Department of Maxillofacial Surgery, Townsville Hospital Douglas, Queensland, Australia

${ }^{2,3}$ Department of Maxillofacial Surgery, Lismore Base Hospital Lismore, New South Wales, Australia

Corresponding Author: Mehmet Oztel, Department of Maxillofacial Surgery, Townsville Hospital, Douglas, Queensland Australia, e-mail: mehmet.oztel@my.jcu.edu.au
}

\section{Source of support: Nil}

Conflict of interest: None

\section{INTRODUCTION}

In modern dentistry, dental implant plays an important role in dental rehabilitation. Its use is widespread and predictable, with survival rates approaching 95\%. ${ }^{1}$ Its growing use can be attributed to the fact that it offers patients a more sophisticated reconstructive alternative, conserving the tooth structure of the residual dentition and eliminating the need for removable prostheses. ${ }^{2}$ Typically, the hallmark of a successful dental implant is when there has been osseointegration at the implant-bone interface. If this fails, then a fibro-osseous integration occurs at the interface resulting in implant instability and ultimately failure (Fig. 1).

Often, placement of an implant requires a significant financial contribution from patients; as such, clinicians should be aware of any potential risk factors that may affect implant osseointegration and failure. Recognizing

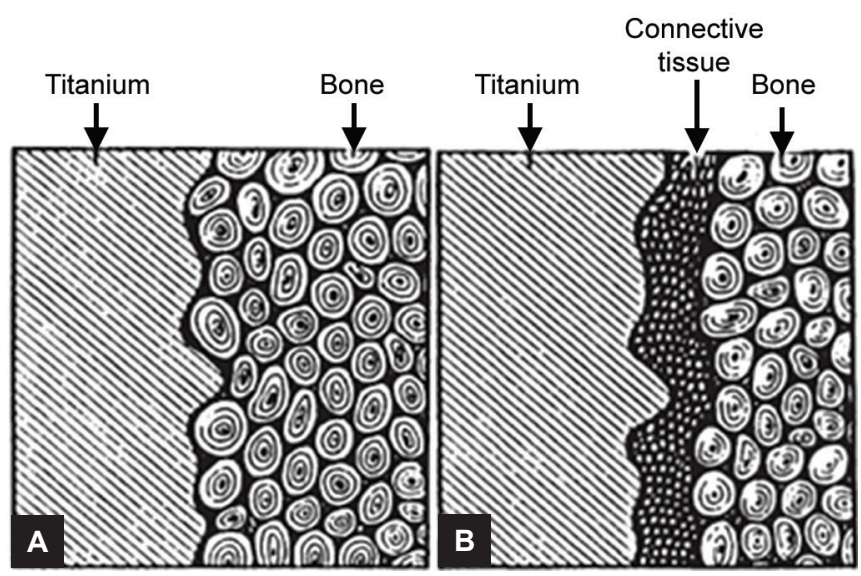

Figs 1A and B: (A) Osseointegration observed at implant-bone interface; and (B) Fibro-osseous integration with formation of connective tissue at implant-bone interface 
Table 1: Implant failures

\begin{tabular}{llllllllll}
\hline & & & & Immediate/ & Stage & \multicolumn{3}{c}{ Surgeon } \\
Age & BMI & Smoker & Diabetes & delayed & 1 or 2 & Length/width $(\mathrm{mm})$ & Site & 1 or 2 & Explanation for failure \\
\hline 68 & 25 & No & No & Delayed & 1 & $15 / 5$ & 13 & 2 & Failure of osseointegration \\
65 & 21 & No & No & Immediate & 1 & $13 / 5$ & 21 & 2 & Failure of osseointegration \\
71 & 31 & No & Yes & Delayed & 1 & $10 / 4$ & 21 & 2 & Failure of osseointegration \\
71 & 30 & No & Yes & Delayed & 1 & $10 / 4$ & 21 & 2 & Failure of osseointegration \\
60 & 35 & No & No & Immediate & 1 & $8.5 / 5$ & 23 & 2 & Failed primary stability \\
69 & 21.4 & No & No & Delayed & 2 & $13 / 3.25$ & 27 & 2 & Failure of osseointegration \\
58 & 23 & No & No & Delayed & 1 & $13 / 5$ & 43 & 1 & Failure of osseointegration \\
60 & 33 & Yes & Yes & Delayed & 1 & $13 / 5$ & 25 & 1 & Peri-implantitis \\
69 & 35 & No & No & Immediate & 2 & $11.5 / 4$ & 11 & 1 & Failure of osseointegration \\
54 & 30.5 & No & No & Immediate & 1 & $8.5 / 5$ & 21 & 1 & Failure of osseointegration \\
61 & 33 & No & Yes & Delayed & 2 & $8.5 / 5$ & 15 & 1 & Failed primary stability \\
47 & 31 & No & No & Immediate & 1 & $8.5 / 5$ & 36 & 2 & Failed primary stability \\
61 & 26.2 & No & No & Delayed & 2 & $10 / 4$ & 15 & 1 & Failed primary stability \\
54 & 33 & No & No & Immediate & 1 & $13 / 5$ & 13 & 1 & Failure of osseointegration \\
66 & 23.7 & No & No & Immediate & 2 & $10 / 4$ & 46 & 1 & Failed primary stability \\
\hline
\end{tabular}

conditions that place patients at a higher risk of complications will allow clinicians to refine treatment plans and optimize outcomes. ${ }^{1}$ A number of factors have been suggested in the literature to affect implant survival, such as implant location, surgical technique, implant dimensions, and patient-related factors, such as age, BMI, smoking, and DM. However, there still appears to be a wide disparity in the literature relating to the impact of these risk factors on implant failure (Table 1). As such, this study aims to identify which risk factors are associated with implant failure using Biomet 3i NanoTite Tapered implants in a regional center.

\section{MATERIALS AND METHODS}

Data pertaining to patients who received one or more dental implants from 2011 to 2013 in a regional center were retrospectively reviewed. Patients were followed up until the end of 2015. A total of 302 Biomet $3 i$ NanoTite Tapered Certain implants (Warsaw, Indiana, United States) were placed in 177 patients by two surgeons.
The main outcome of interest was implant failure, defined as an implant requiring replacement. Patients were assessed clinically and with intraoral radiography for any form of complication including peri-implantitis and implant mobility, wound dehiscence, infection, persistent bleeding, or lost/broken abutments. A number of variables were investigated including age, gender, DM, smoking, BMI, implant location, and surgical technique.

The data were analyzed using Excel and Statistical Package for the Social Sciences software. Chi-squared test and Pearson coefficient were used to determine the association between variables and failure of implant; $p<0.05$ was considered to be statistically significant. The odds ratio and 95\% confidence interval (CI) were calculated for variables, which displayed significant associations.

\section{RESULTS}

Within the follow-up period, we identified 23 patients who had sustained complications. Fifteen patients failed requiring replacement, giving an overall success rate of $95 \%$. Table 2 summarizes patient information of all

Table 2: Comparison of the previous studies

\begin{tabular}{|c|c|c|c|c|c|c|c|c|c|c|}
\hline \multirow[b]{2}{*}{ Study } & \multirow[b]{2}{*}{ Year } & \multirow[b]{2}{*}{ Patients } & \multirow[b]{2}{*}{ Implants } & \multirow[b]{2}{*}{$D M$} & \multirow[b]{2}{*}{ Smoking } & \multicolumn{5}{|c|}{ Risk factors associated with failure } \\
\hline & & & & & & $\begin{array}{l}\text { Implant } \\
\text { diameter }\end{array}$ & $\begin{array}{l}\text { Implant } \\
\text { length }\end{array}$ & $\begin{array}{l}\text { Implant } \\
\text { Iocation }\end{array}$ & $\begin{array}{l}\text { Surgical } \\
\text { technique }\end{array}$ & Age \\
\hline Alsaadi et al ${ }^{3}$ & 2007 & 2004 & 6946 & - & + & + & + & + & ** & - \\
\hline Bornstein et $\mathrm{al}^{4}$ & 2008 & 1206 & 1817 & ** & + & ** & ** & - & ** & - \\
\hline Busenlechner et $\mathrm{al}^{2}$ & 2014 & 4316 & 13147 & - & + & - & - & - & $* *$ & - \\
\hline Daubert et $\mathrm{al}^{5}$ & 2015 & 114 & 225 & - & ** & + & ** & ** & + & ** \\
\hline Esposito et $\mathrm{al}^{6}$ & 2009 & 239 & 761 & ** & ** & ** & $* *$ & ** & - & $* *$ \\
\hline Grisar et $\mathrm{al}^{7}$ & 2017 & 509 & 1139 & ** & + & + & ** & ** & ** & ** \\
\hline Hasegawa et $\mathrm{al}^{8}$ & 2016 & * & 907 & ** & No & - & + & ** & ** & + \\
\hline Moy et $\mathrm{al}^{9}$ & 2005 & 1140 & 4680 & + & + & ** & $* *$ & - & $* *$ & + \\
\hline Vehemente et al ${ }^{10}$ & 2002 & 677 & 677 & ** & + & ** & $* *$ & - & + & - \\
\hline
\end{tabular}

+Statistically significant association with implant failure; -no statistically significant association with implant failure; *Not specified; **Not evaluated 
Table 3: Variable risk factors and implant failure

\begin{tabular}{|c|c|c|c|}
\hline Risk factor & $\begin{array}{l}\text { Implant failure } \\
\text { (failure rate) } \\
(\%)\end{array}$ & $\begin{array}{l}\text { Implant } \\
\text { success } \\
\text { (success rate) }\end{array}$ & $p$-value \\
\hline Sample size & $15(5)$ & $287(95)$ & \\
\hline Gender & & & 0.85 \\
\hline Male & $7(5.2)$ & $127(94.8)$ & \\
\hline Female & $8(4.8)$ & $160(95.2)$ & \\
\hline Age (years) & & & 0.97 \\
\hline$<60$ & $5(9.1)$ & $50(90.9)$ & \\
\hline$\geq 60$ & $10(8.9)$ & $102(91.1)$ & \\
\hline$B M I$ & & & 0.01 \\
\hline$<30$ & $7(10.8)$ & $58(89.2)$ & \\
\hline$\geq 30$ & $8(3.2)$ & $236(96.7)$ & \\
\hline Implant location & & & 0.56 \\
\hline Anterior & $9(5.7)$ & $150(94.3)$ & \\
\hline Posterior & $6(4.2)$ & $137(95.8)$ & \\
\hline Jaw & & & 0.02 \\
\hline Maxilla & $12(7.7)$ & $143(92.3)$ & \\
\hline Mandible & $3(2)$ & $144(98)$ & \\
\hline Implant length & & & $<0.05$ \\
\hline$<10 \mathrm{~mm}$ & $8(24.2)$ & $25(75.8)$ & \\
\hline$\geq 10 \mathrm{~mm}$ & $7(2.6)$ & $262(97.4)$ & \\
\hline Implant width & & & 0.76 \\
\hline$\leq 3.5 \mathrm{~mm}$ & $1(7.1)$ & $14(92.9)$ & \\
\hline$\geq 4 \mathrm{~mm}$ & $14(5.9)$ & $273(94.1)$ & \\
\hline Surgical technique & & & $<0.05$ \\
\hline Immediate & $10(11.6)$ & $76(88.4)$ & \\
\hline Delayed & $5(2.3)$ & $211(97.7)$ & \\
\hline Surgical technique & & & $<0.05$ \\
\hline One-stage surgery & $10(13.5)$ & $64(86.5)$ & \\
\hline Two-stage surgery & $5(2.2)$ & $223(97.8)$ & \\
\hline Smoking & & & 0.56 \\
\hline Yes & $1(3)$ & $33(97)$ & \\
\hline No & $14(5.2)$ & $254(94.8)$ & \\
\hline$D M$ & & & 0.03 \\
\hline Yes & $3(15)$ & $17(85)$ & \\
\hline No & $12(4.3)$ & $270(95.7)$ & \\
\hline Surgeon & & & 0.38 \\
\hline Surgeon 1 & $8(4.1)$ & $185(95.9)$ & \\
\hline Surgeon 2 & $7(6.4)$ & $102(93.6)$ & \\
\hline
\end{tabular}

failed implants. Three patients presented with wound dehiscence, three with broken/lost abutments, and two with persistent bleeding. The mean follow-up time was 36.3 months ( $25-51$ months). Table 3 summarizes variable factors involved with implant failure.

The mean age of participants was $60.2 \pm 15.1(18-94)$ years. Nearly $67 \%$ of failed implants and $74 \%$ of all complications occurred in those who were 60 years of age or greater, with the youngest being 47 years.

The number of implants placed in the maxilla and mandible was comparable, yet $80 \%$ of implant failures occurred in the maxilla.

About $67 \%$ of failures occurred in single-staged (nonsubmerged) implants. Pearson coefficient demonstrated a weak yet positive correlation between single-stage implants and failure $(\mathrm{r}=0.3)$.

Twenty patients within the sample had been diagnosed with DM. Although there was no relationship with implant failure, all the patients who presented with wound dehiscence had a background of DM. Pearson coefficient demonstrated a positive relationship between the two variables $(r=0.4)$.

Gender, BMI, implant dimensions, smoking, and surgical operator did not have any impact on implant survival or complications.

\section{DISCUSSION}

Implant placement can present a technical challenge for operators. Figure 2 shows the various steps for a single implant placed as a two-stage technique. The overall survival rate for implants within this study was $95 \%$ over a period of 3 to 5 years. This is consistent with that of the literature which in recent years has reported a survival rate of 83 to $97 \%{ }^{7,8,11}$

Although $67 \%$ of implant failures occurred in those who were $>60$ years, this study did not produce a statistically significant result. The literature is divided as to whether advancing age is truly a risk factor for failure. ${ }^{12,13}$ It has been suggested that with advancing age, there are changes in bone and collagen that may result in longer healing periods. An important note to make is that older patients may also have more alveolar bone atrophy, resulting in reduced bone volume and increasing the rate of failure. Ultimately, implants have been placed successfully in the elderly population; ${ }^{14}$ however, more research is needed to make tangible and clinically applicable conclusions.

Although some studies within the literature suggest that implant site does not have an effect on implant survival, ${ }^{15}$ our results found a significant difference in survival when comparing implants placed in the maxilla and mandible. We found that $80 \%$ of failures occurred in implants placed in the maxilla $(p=0.02)$. These results are in line with a number of other studies that produced similar results. ${ }^{16}$ We believe that the lower bone density in the upper jaw coupled with low bone volume seen in alveolar atrophy results in the higher failure rate. Despite this, success rates of implants in the maxilla were still at an acceptable $92.3 \%$.

The most common length and width of the implants used were with $11.5 \mathrm{~mm}(8-15)$ and $4 \mathrm{~mm}(3.25-6)$ respectively. A number of studies have identified that an implant length $<10 \mathrm{~mm}$ was observed as having a success rate as low as $85.3 \% .{ }^{17}$ With our limited sample size, our results showed a success rate of $75.8 \%$ in implants $<10 \mathrm{~mm}$ (odds ratio of $11.97,95 \%$ CI: 4.00-35.77, p < 0.05). No 

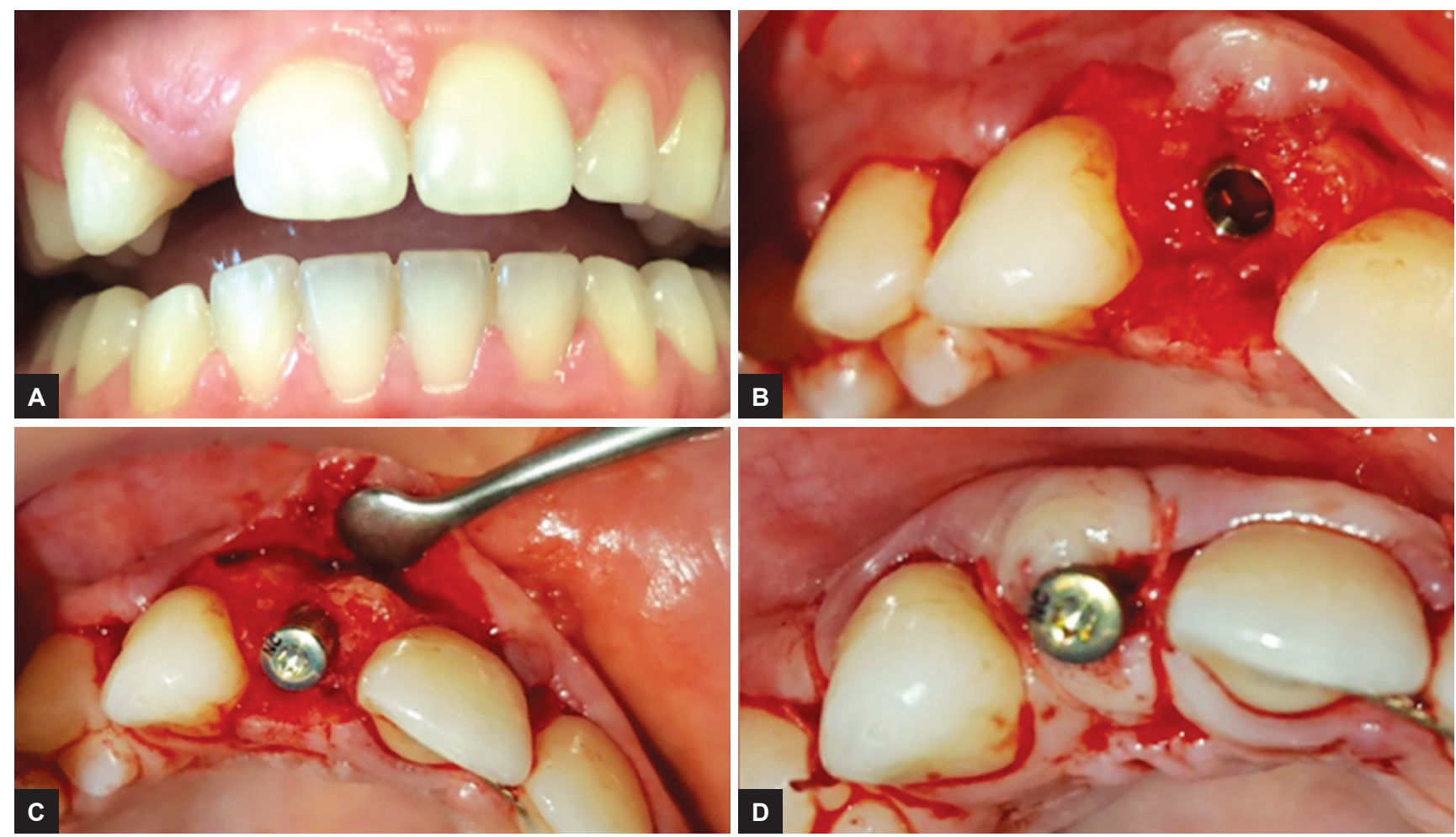

Figs 2A to D: Technical steps in single-stage implant placement: (A) Preoperative view; (B) dental implant in place without healing abutment; $(C)$ healing abutment in place; and $(D)$ tissues sutured closed with healing abutment exposed

statistically significant differences were found in relation to implant width.

Surgical technique is another important characteristic to consider. We found that single-stage implants (nonsubmerged) had a lower success rate of $85.5 \%$ compared with those that were performed as two-stage technique (submerged). In the literature, there continues to be disparity as to whether it makes any impact on implant failure; ultimately, there is a lack of high-quality evidence to be able to make any definitive conclusions. ${ }^{15}$ Despite the lack of evidence, we focused single-stage placement on partially dentate patients. Two-stage placement was used in circumstances in which adequate initial stability was not achieved, barriers were required for regeneration, or a removable prosthesis was transmitting excessive forces on the abutment, similar to what is suggested in the literature. ${ }^{6}$

The frequency of diabetes is growing, with an estimated 350 million people being affected by $2008 .{ }^{18}$ As such, the effect of poorly managed DM and implant failure has been an important topic in the literature. Some authors have found that the presence of diabetes has little impact on implant failure, ${ }^{19}$ whereas others would agree that poorly controlled DM has been linked to impaired osseointegration, elevated risk of peri-implantitis and periodontitis. ${ }^{20}$ Within our study, we found that the failure rate of those with DM was a lower $85 \%$ (odds ratio $3.97,95 \%$ CI: $1.02-15.4, p<0.05)$. Furthermore, all three patients who presented with wound dehiscence and impaired healing had a diagnosis of DM. Despite this, there are a number of limitations within this study that we must consider before making definitive conclusions. First, the absence of glycated hemoglobin of patients within the sample prevents us from formulating conclusions related to poor diabetic control and subsequent complications. Furthermore, a larger sample with a longer follow-up period as a follow-up study would help in analyzing the true relationship further.

\section{CONCLUSION}

This study has demonstrated that the incidence of implant failure and its complications is affected by a number of important factors that clinicians should consider when assessing patients. A follow-up study with a larger sample size, longer follow-up period, and details of the type of prosthetic rehabilitation would be beneficial in producing more definitive conclusions, which may improve clinical practice.

\section{ACKNOWLEDGMENT}

Authors would like to thank http:/ / facialsurgeryuk.com and pocketdentistry.com for the images used.

\section{REFERENCES}

1. Naujokat H, Kunzendorf B, Wiltfang J. Dental implants and diabetes mellitus - a systematic review. Int J Implant Dent 2016 Dec;2(1):5. 
2. Busenlechner D, Fürhauser R, Haas R, Watzek G, Mailath G, Pommer B. Long-term implant success at the academy for oral implantology: 8-year follow-up and risk factor analysis. J Periodontal Implant Sci 2014 Jun;44(3):102-108.

3. Alsaadi G, Quirynen M, Komárek A, van Steenberghe D. Impact of local and systemic factors on the incidence of oral implant failures, up to abutment connection. J Clin Periodontol 2007 Jul;34(7):610-617.

4. Bornstein MM, Halbritter S, Harnisch H, Weber HP, Buser D. A retrospective analysis of patients referred for implant placement to a specialty clinic: indications, surgical procedures, and early failures. Int J Oral Maxillofac Implants 2008 Nov-Dec;23(6):1109-1116.

5. Daubert DM, Weinstein BF, Bordin S, Leroux BG, Flemming TF. Prevalence and predictive factors for peri-implant disease and implant failure: a cross-sectional analysis. J Periodontol 2015 Mar;86(3):337-347.

6. Esposito M, Grusovin MG, Chew YS, Coulthard P, Worthington HV. One-stage versus two-stage implant placement. A Cochrane systematic review of randomised controlled clinical trials. Eur J Oral Implantol 2009 Summer;2(2):91-99.

7. Grisar K, Sinha D, Schoenaers J, Dormaar T, Politis C. Retrospective analysis of dental implants placed between 2012 and 2014: indications, risk factors, and early survival. Int J Oral Maxillofac Implants 2017 May/Jun;32(3):649-654.

8. Hasegawa T, Kawabata S, Takeda D, Iwata E, Saito I, Arimoto S, Kimoto A, Akashi M, Suzuki H, Komori T. Survival of Brånemark System Mk III implants and analysis of risk factors associated with implant failure. Int J Oral Maxillofac Surg 2017 Feb;46(2):267-273.

9. Moy PK, Medina D, Shetty V, Aghaloo TL. Dental implant failure rates and associated risk factors. Int J Oral Maxillofac Implants 2005 Jul-Aug;20(4):569-577.

10. Vehemente VA, Chuang SK, Daher S, Muftu A, Dodson TB. Risk factors affecting dental implant survival. J Oral Implantol 2002;28(2):74-81.
11. Schwartz-Arad D, Laviv A, Levin L. Failure causes, timing, and cluster behavior: an 8-year study of dental implants. Implant Dent 2008 Jun;17(2):200-207.

12. Chen H, Liu N, Xu X, Qu X, Lu E. Smoking, radiotherapy, diabetes and osteoporosis as risk factors for dental implant failure: a meta-analysis. PLoS One 2013 Aug;8(8):e71955.

13. Palma-Carrió $C$, Maestre-Ferrín L, Peñarrocha-Oltra D, Peñarrocha-Diago MA, Peñarrocha-Diago M. Risk factors associated with early failure of dental implants. A literature review. Med Oral Patol Oral Cir Bucal 2011 Jul;16(4):e514-e517.

14. Compton SM, Clark D, Chan S, Kuc I, Wubie BA, Levin L. Dental implants in the elderly population: along-term followup. Int J Oral Maxillofac Implants 2017 Jan/Feb;32(1):164-170.

15. Lang NP, Pun L, Lau KY, Li KY, Wong MC. A systematic review on survival and success rates of implants placed immediately into fresh extraction sockets after at least 1 year. Clin Oral Implants Res 2012 Feb;23 Suppl 5:39-66.

16. Stach RM, Kohles SS. A meta-analysis examining the clinical survivability of machined-surfaced and osseotite implants in poor-quality bone. Implant Dent 2003;12(1):87-96.

17. Misch CE, Steignga J, Barboza E, Misch-Dietsh F, Cianciola LJ, Kazor C. Short dental implants in posterior partial edentulism: a multicenter retrospective 6-year case series study. J Periodontol 2006 Aug;77(8):1340-1347.

18. DanaeiG,FinucaneMM,LuY,Singh GM,Cowan MJ,PaciorekCJ, Lin JK, Farzadfar F, Khang YH, Stevens GA, et al. National, regional, and global trends in fasting plasma glucose and diabetes prevalence since 1980: systematic analysis of health examination surveys and epidemiological studies with 370 country-years and 2.7 million participants. Lancet 2011 Jul;378(9785):31-40.

19. Oates TW, Huynh-Ba G. Diabetes effects on dental implant survival. Forum Implantol 2012 Feb;8(2):7-14.

20. Razmara F, Kazemian M. Etiology, complications, key systemic and environmental risk factors in dental implant failure. Int J Contemp Dent Med Rev 2015;81:1-6. 